\title{
Enunciación
}

\section{Tres lecturas sobre trayectos comunicacionales experimentales}

\author{
Three Approaches to Experimental Communication Trajectories
}

\author{
José Daniel Lencina*
}

\section{Resumen}

El artículo expone una aproximación acerca de los que se han denominado trayectos comunicacionales experimentales desde la mirada de tres autores que suponen una perspectiva crítica a la captura del capital de las subjetividades del presente. De esta manera, Giorgio Agamben, Gilles Deleuze y Michel Foucault proveen, a través de sus respectivos aportes al pensamiento, las lentes teóricas que se constituyen en insumos para reflexionar sobre aquellos trayectos comunicacionales que emprenden una empresa crítica a la discursividad mayoritaria. Así, profanación al capital, actitud esquizo y parresía se constituyen en ejes que sirven como base para imaginar, a partir de la comunicación, otros mundos posibles, alternativas existenciales a las de la biopolítica neoliberal y, en última instancia, posibilidades liberadoras.

Palabras clave: comunicación, periodismo, libertad, crítica, capitalismo.

\begin{abstract}
This article presents an approach towards what has been called experimental communication trajectories from the perspective of three authors, which constitute a critical view on the capture of subjectivities by the capital. In this way, Giorgio Agamben, Gilles Deleuze, and Michel Foucault provide, by means of their respective contributions to thought, the theoretical lenses that become inputs to reflect upon those communicational paths that undertake a critique of hegemonic discursivity. Thus, profanation of capital, schizoid attitude, and parrhesia constitute axes of thought that serve as basis for imagining other worlds from communication, existential alternatives different to those of neoliberal biopolitics and, ultimately, liberating possibilities.
\end{abstract}

Keywords: communication, journalism, freedom, critical thinking, capitalism.

\footnotetext{
* Periodista e investigador argentino, doctorando en Estudios Sociales de la Universidad Distrital Francisco José de Caldas de Bogotá, Colombia, en la línea de Subjetividades, Diferencias y Narrativas. Publica sus columnas y avances investigativos en su portal web https://parresia-online.com/. Correos electrónicos: jdlencina@correo.udistrital.edu.co; contacto@parresia-online.com.

ORCID: https://orcid.org/0000-0003-3477-3864
}

Cómo citar: Lencina, J. D. (2021). Tres lecturas sobre trayectos comunicacionales experimentales. Enunciación, 26(2), $231-243$.

DOI: https://doi.org/10.14483/22486798.17824 


\section{Introducción}

El presente artículo es resultado de una serie de problematizaciones que se proponen en el marco de la investigación que se adelanta bajo el título "La producción biopolítica de la subjetividad del periodista en América Latina (2005-2022)", en el grupo de investigación Vivencias, del Doctorado en Estudios Sociales (DES) de la Universidad Distrital Francisco José de Caldas (Bogotá, Colombia).

Como expresa el título de la investigación, lo que se propone poner en tela de discusión es la producción de la subjetividad del periodista latinoamericano en términos de la biopolítica del presente. Es decir, dentro de lo que Michel Foucault aborda en cuanto formas de gobierno que se ejercen sobre los sujetos, en este caso, de un sujeto específico que no es otro sino el periodista y el comunicador social de esta región del mundo.

$\mathrm{Y}$ en este marco es que se presentan ciertas resistencias a ese gobierno, a ese ejercicio del poder que encuentra en los cuerpos de los sujetos su primer territorio de despliegue. Tales resistencias hallan en esos mismos cuerpos la superficie de expresión de la crítica que, en el campo comunicacional, se dan en la forma de lo que hemos denominado trayectos comunicacionales experimentales.

Se trata de aquellas experimentaciones que por alguna circunstancia optaron por recorrer trayectorias por fuera de las demarcadas por los denominados grandes medios hegemónicos de comunicación, que cuestionan las verdades con las que el imperio autoconstruye su legitimidad (Hardt y Negri, 2000), que emplean sus propias anatomías para el ejercicio crítico sobre el presente, y que se exponen a sus riesgos intrínsecos. Experiencias como ElDiario.es en España, El Destape en Argentina, MediaPart en Francia, La Nueva Prensa en Colombia, The Intercept en Estados Unidos y muchas otras en el mundo dan cuenta de que aquellas verdades son disputadas desde lugares minoritarios, contrahegemónicos, de resistencia, lo que da lugar a un examen sobre la producción discursiva del mundo en que vivimos. ¿Qué nos dicen Agamben, Deleuze y Guattari, y el mismo Foucault acerca de estas experimentaciones críticas, y cómo las vinculamos con aquellas que se advierten en el campo de los medios de comunicación? Ya sea que se las encuadre en los márgenes del pensamiento posestructuralista, foucaultiano, deleuziano, o como prefiera denominarse, se trata -en definitiva- de trayectos que emprenden una mirada inquisidora del presente en tanto interpretación del poder y del empleo de los recursos simbólicos disponibles, de las luchas y de las condiciones de posibilidad para la producción de subjetividades con el propósito de "visibilizar aquello que organiza, regula y articula una vida social en un momento determinado del tiempo" (Batanelo García, 2015, p. 11). Así, Foucault presenta el valor de la crítica y del decir verdadero, de la parresía, sobre lo que se profundizará en ulteriores apartados.

Estas son algunas de las cuestiones cuyos trazos se intentan abordar en este espacio, como ya se mencionó, estimuladas por una problematización de la subjetividad de los periodistas cercana a una biopolítica de la comunicación. Y es precisamente Foucault quien a mediados de la década de 1970 inaugura sus estudios sobre la biopolítica y la razón gubernamental a partir de las conferencias ofrecidas en la Universidad de Río de Janeiro. No obstante, específicamente en el curso dictado en el Collège de France entre enero y febrero de 1979, volcó todos sus esfuerzos a estos temas. Tal curso fue compilado, editado y publicado por primera vez en 2004 bajo el título El nacimiento de la biopolítica (2007), lo que, sin embargo, no impidió que desde tiempo antes se emprendieran estudios dentro del rango categorial biopolítico, entre los que se encuentran los de Giorgio Agamben y Gilles Deleuze junto a Félix Guattari, entre otros. Ahora bien, no faltan quienes advierten que la ausencia de estos aportes en aquellos trabajos produce "direcciones y rendimientos políticos muy diferentes a las direcciones y rendimientos políticos del trabajo de Foucault" (Salinas Araya, 2014, p. 17). 
Aquí es preciso hacer un alto para el tratamiento de cierta terminología y asunciones teóricas que tal vez no sean totalmente naturales en la jerga periodística, como las cuestiones sobre el sujeto y la subjetividad, que asimismo no exhiben unicidad alguna. Estimulada por la tradición nietzscheana, una de las rupturas más drásticas se produjo a partir de la década de 1960 desde el pensamiento de Michel Foucault, desde quien se corre el foco de un sujeto trascendente y esencial, para pasar a una consideración de las tramas de poder, los discursos y dispositivos que afectan a los individuos para producirlos social e históricamente. Es necesario advertir la relevancia que el pensador francés le da al cuidado de sí como acción ética sobre el gobierno que le es ejercido, haciendo que la subjetividad no sea sino un resultante entre estas tensiones: "obligación de todo individuo de cuidar de sí mismo, inmediatamente ligada, como su condición, al conocimiento de sí. No podemos ocuparnos de nosotros mismos sin conocernos" (Foucault, 2009, p. 60). En esta línea -que puede Ilamarse posestructuralista- es posible también ubicar al pensamiento de Gilles Deleuze (1994), para quien no habría un sujeto como tal, sino líneas de trayectorias en constante movimiento que se integran a un devenir existencial que nunca acaba por determinarse, indeterminación que se da por la cualidad de afectar y de ser afectado; se trata de una ontología de la diferencia en el ser: "creemos que la noción de sujeto ha perdido mucho de su interés en nombre de las singularidades pre-individuales y de las individuaciones no personales" (p. 2). En tanto que, para Félix Guattari -con quien Deleuze compartió los proyectos de El anti-Edipo en 1972, Mil mesetas en 1980 y ¿Qué es la filosofía? en 1991-, la subjetividad es resultante de procesos de producción en los que intervienen las máquinas del capital: medios de comunicación, sistemas de propagandas, políticas basadas en estadísticas y encuestas, etc. En consecuencia, aquí no hay sujeto sino una subjetividad producida en clave del mercado (Fourquet, 2007).
También pueden mencionarse otras corrientes como los Estudios Culturales o la Antropología Cultural. Para los primeros, que emergen en los años 1960 en Inglaterra y en los que se destacan autores como Richard Hoggart, Raymond Williams y Edward Thompson -entre otros-, es clave comprender las cuestiones de la experiencia y de la cultura para producir la subjetividad; la experiencia en cuanto significación e interpretación de los discursos disponibles, y la cultura en cuanto cultura popular. A esto, la Antropología Cultural le adiciona la pregunta por el sentido en cuanto insumo al que los individuos recurren para comprender el mundo (Aquino Moreschi, 2013, pp. 264-275). No obstante, son los abordajes realizados por la primera de las referidas -es decir, por la línea posestructuralista, foucaultiana o deleuziana-, los que operan como eje problematizador sobre las subjetividades en esta propuesta. Este es el contexto teórico y algunas de las discusiones que se proponen en este espacio de debate sobre las subjetividades de los periodistas latinoamericanos.

\section{Profanando el capital}

En términos de organización, esta parte de la presentación se propone alrededor de dos ejes principales: por un lado, se aborda la cuestión acerca de las experimentaciones en el campo de los medios de comunicación como posibilidad profanatoria al poder del capital, en cuanto construcción simbólica de autolegitimación apoyada en las virtudes de los dispositivos mediáticos. Emerge, entonces, la pregunta acerca de si estos ensayos experimentales representan una auténtica amenaza a la vitalidad neoliberal, es decir, si alcanzan un rango de profanación al lenguaje o, en todo caso, si son secularizaciones a la verdad incapaces de alterar tal orden. Por otra parte, se plantea pensar que tales ejercicios no solo procuran visibilizar ciertos discursos en un determinado marco societal, es decir, en términos de Agamben (1998), con el bios (pp. 16-18). Lejos de ello, lo que está en controversia es 
la integridad de la vida misma en sus formas más elementales; dígase, con el zoe.

¿Existe, en el tiempo presente, sacrilegio más alto que aquel que profana las verdades del capital? Asumiendo la profanación como una especial forma de negligencia que visibiliza (desacraliza) los dispositivos y modos de gobierno que el capitalismo eleva como religión -en continuidad con Benjamin-, el desafío ante la biopolítica neoliberal se presenta como toda una irreverencia en el terreno de la producción simbólica.

Los juristas romanos sabían perfectamente qué significaba "profanar". Sagradas o religiosas eran las cosas que pertenecían de algún modo a los dioses. Como tales, ellas eran sustraídas al libre uso y al comercio de los hombres, no podían ser vendidas ni dadas en préstamo, cedidas en usufructo o gravadas de servidumbre. Sacrílego era todo acto que violara o infringiera esta especial indisponibilidad, que las reservaba exclusivamente a los dioses celestes (y entonces eran Ilamadas propiamente "sagradas") o infernales (en este caso, se las Ilamaba simplemente "religiosas"). Y si consagrar (sacrare) era el término que designaba la salida de las cosas de la esfera del derecho humano, profanar significaba por el contrario restituirlos al libre uso de los hombres. (Agamben, 2005, p. 97)

En el planteamiento que se viene desarrollando, lo que pertenece al dios del capital es la palabra sacralizada de los tradicionales medios de comunicación y ahora profanada, puesta a disponibilidad de los hombres desde los trayectos experimentales críticos. Pero, ir en contrasentido a la verdad legitimada, arrogarse el estatus para alzar la voz resulta ser un peligroso juego que puede incluso llegar a costar la vida. Y ese fue el costo que debieron asumir, en el ámbito de legitimación de los medios de comunicación, quienes acometieron contra la sanctum verum afines a las lógicas del mercado, incluso en tiempos de pandemia por covid-19. Iniciativas como El destape en Argentina, ElDiario.es en España, The Intercept en
Estados Unidos, MediaPart en Francia y muchos otros no son otra cosa que experimentaciones en la búsqueda de una supervivencia que no alcanzaron, por ejemplo, otros espacios enunciativos como en su momento lo fue $6,7,8$ en la TV Pública de Argentina. Tales trayectos se presentan en la forma de irreverentes juegos con importantes cuotas de blasfemia. Pero ¿cuál es la naturaleza del juego como práctica que aparta a la humanidad de la esfera de lo sagrado? Para Agamben (2005),

Esto significa que el juego libera y aparta a la humanidad de la esfera de lo sagrado, pero sin abolirla simplemente. El uso al cual es restituido lo sagrado es un uso especial, que no coincide con el consumo utilitario. La "profanación" del juego no atañe, en efecto, solo a la esfera religiosa. Los niños, que juegan con cualquier trasto viejo que encuentran, transforman en juguete aun aquello que pertenece a la esfera de la economía, de la guerra, del derecho y de las otras actividades que estamos acostumbrados a considerar como serias. Un automóvil, un arma de fuego, un contrato jurídico se transforman de golpe en juguetes. Lo que tienen en común estos casos con los casos de profanación de lo sagrado es el pasaje de una religio, que es sentida ya como falsa y opresiva, a la negligencia como verdadera religio. Y esto no significa descuido (no hay atención que se compare con la del niño mientras juega), sino una nueva dimensión del uso, que niños y filósofos entregan a la humanidad. Se trata de un tipo de uso como el que debía tener en mente Walter Benjamin, cuando escribió, en El nuevo abogado, que el derecho nunca aplicado, sino solamente estudiado es la puerta de la justicia. Así como la religio no ya observada, sino jugada abre la puerta del uso, las potencias de la economía, del derecho y de la política desactivadas en el juego se convienen en la puerta de una nueva felicidad. (pp. 100-101)

Así como un automóvil, un arma o un contrato jurídico son transformados en juguetes, los medios de comunicación, o más bien el lenguaje pronunciado desde los espacios consagrados por el capital, 
es forzado a abandonar su sacro lugar y arrojado al barro de lo profano. A través de estos ejercicios de experimentación mediática es que un nuevo uso de la palabra se convierte en un objeto de juego que atenta contra la religión imperante, aquella sostenida en las prácticas por los rituales de consumo. Y si bien "restituir el juego a su vocación puramente profana es una tarea política" (Agamben, 2005, p. 101), no deja de admitir problematizaciones sobre su suficiencia para remover los profundos cimientos del poder: ¿Puede, a partir de la producción simbólica resistente que emerge de espacios discursivos-otros, sentirse amenazada la salud del capital?; ¿tiene esa crítica la potencia necesaria para, desde allí, promover la emergencia de otros órdenes?; asumiendo que estas empresas no dispongan de esa capacidad, ise puede decir que alcanzan el rango de secularizaciones de la palabra más que de profanaciones? Pues para poder ser elevados a ese escalón, tales ensayos deben contar con el brío suficiente para alterar el poder vigente, en vez de solo cambiarlo de lugar.

Para graficar el punto precedentemente señalado, obsérvese el Reporte de Información Digital del Reuters Institute 2019, el cual detalla que MediaPart es la tercera publicación de mayor confianza en Francia, mientras que EIDiario.es es el cuarto periódico digital más frecuentado por los nativos digitales de España (Newman et al., 2019, pp. 84, 108-109). No obstante, ¿representa esto que se haya producido una profanación al poder simbólico del capital, o implica que dentro de la misma condición haya habido un cambio de manos del poder, aunque dejándolo intacto? Si fue lo segundo lo que aconteció, puede decirse que la práctica política de pronunciación discursiva fue arrebatada a los medios tradicionalmente dominantes y luego secularizada pero, para que el poder haya sido profanado, ¿es requisito la alteración de los órdenes dispuestos por el capital?

En cualquier caso, el lenguaje se constituye en juguete, dándole otra dimensión a su uso en un acto político con implicancias de nueva felicidad que, sin embargo, amenaza a la religión cultural del capital. No obstante, Agamben (2005) plantea que el juego en algún momento termina, y las esferas del consumo y del espectáculo (propios de la fase extrema del capitalismo y destinados a operar en la creación de un improfanable por medio de la captura de los comportamientos profanatorios) no hacen más que convertirse en alimento de aquello que busca sobrevivir y crecer: "En su fase extrema, el capitalismo no es más que un gigantesco dispositivo de captura de los medios puros, es decir, de los comportamientos profanatorios" (p. 114). Uno de esos medios puros es el lenguaje, cuyo proyecto político, si no ha sido cumplido hasta el momento, deberá ser asumido por la siguiente generación.

El espectáculo ahora aliena el ser lingüístico, el lenguaje en tanto bien común. Es la comunicación la que ahora es expropiada, separada y colocada en la esfera especial de la separación (en la esfera espectacular), en la que pareciera que ya no hay posibilidad alguna de usar de otro modo la palabra, más que para regurgitar su nada, su vacío, en un espectáculo y palabrería sin fin. La comunicatividad queda separada en esta esfera autónoma en la que no dice sino su pura nada; pero su lugar lo toma la comunicabilidad, el lenguaje que ya no revela nada o que solo revela la nada de las cosas. (Hernández, 2017, p. 146)

La relevancia política de esta profanación al lenguaje tiene que ver con el descenso del corpus simbólico a los ámbitos más íntimos y cotidianos de la vida, lo que se relaciona incluso con la supervivencia misma. Aquí es posible rescatar el acontecimiento de la pandemia por coronavirus y sus efectos, específicamente vinculado al aumento exponencial del acceso a los medios de comunicación en el mundo. De acuerdo con el informe de las agencias The Gobal Web Index y el Panel LIVE de Wavemaker, durante las cuarentenas la población mundial estuvo expuesta a los medios a niveles sin precedentes, llegando incluso a producir bloqueos en streamings y canales de transmisión (World Economic Forum, 2020, p. 11). 
Esto es, resumidamente, que las personas pasaron mucho más tiempo frente a las pantallas como estrategia para hacer más tolerables sus confinamientos. No obstante, tal nivel de exposición lejos está de ser inocente, pues está ataviado por discursos con tejidos confeccionados por relaciones de poder, por una construcción del presente cuyos entrelazamientos son afines a la condición neoliberal (Lazzarato, 2013). Así, la presencia del televisor en el centro de la sala, del computador como medio de trabajo, socialización e información, de un teléfono celular que acentúa su protagonismo como gadget en las vidas de las personas, de la radio permanentemente encendida como compañía, y del periódico que llega a millones de hogares ya sea en soporte impreso o digital, hizo que en tiempos de cuarentena los medios de comunicación se constituyeran en la ventana excluyente a través de la que fue posible acceder al mundo desde la celda de la vida, aunque no como mero medio de contacto, sino también bajo su pose de control. Así, si los medios se constituyen en dispositivos de despliegue de la biopolítica imperial (Hardt y Negri, 2000), el Ilamado a asaltar el poder del capital es mandatorio, lo que en el campo mediático puede alcanzarse con la toma del lenguaje para profanarlo. En última instancia, este acto (que es político) tendrá que ver no solo con la regulación o administración de la vida, ni con la vida en el marco de una socialidad, sino incluso con su misma preservación.

Por eso, experimentaciones que busquen tomar el lenguaje de las consagradas esferas mediáticas se elevan al rango de necesidad existencial. El Destape en Argentina, ElDiario.es en España, MediaPart en Francia, La Nueva Prensa en Colombia, The Intercept en Estados Unidos y otros no solo son estrategias para alzar la voz en el pronunciamiento de otras verdades, sino que su acto de resistencia se vincula con la conservación de la vida, algo que -más que nunca- ha quedado en evidencia con las circunstancias que la humanidad vive en el presente.

\section{Esquizoperiodismo}

Aquí se recurre al trabajo de Gilles Deleuze y Félix Guattari como herramienta para emprender la reflexión de que en el campo de la comunicación y del periodismo se dan ciertas prácticas esquizo en la forma de experimentaciones estéticas que, a su vez, suponen ciertos posicionamientos éticos, políticos y espirituales. El hilo propuesto inicia con la pregunta acerca de si es posible efectuar cambios a partir de la adopción de determinada elección política y visión de la vida. Piénsese en cuánto más cómodos podrían resultar los posicionamientos ajustados a requerimientos gerenciales de organizaciones insertas en dinámicas de mercado propias de la biopolítica neoliberal. Pero ¿qué podría expresar esa comodidad o a qué otras incomodidades podrían dar lugar? Esa (in)comodidad justificaría el tránsito por determinadas líneas que pueden ser duras o molares, que son aquellas donde se encuentran los parámetros de normalización y de control; blandas o moleculares, donde se hallan los tránsitos experimentales que desde algún lugar establecen una crítica al dispositivo duro; o por líneas de fuga, que expresan desterritorializaciones como manifestaciones potentes del deseo. En lo comunicacional, cada una de ellas conlleva determinadas corporalidades y ejercicios de prácticas a mayor o menor distancia de los dispositivos, con distintas relaciones ante la captura del capital.

A este respecto, la accesibilidad a las nuevas tecnologías estimula las esperanzas sobre grados de mayor democratización en el empleo de los recursos discursivos, materializando experimentaciones capaces de manifestar visiones del mundo desde lugares-otros. Se trata de prácticas y de cuerpos indóciles, pero no caprichosos, que expresan lugares y sentires espirituales distantes de todo esencialismo, que desde la potencia de sus contingencias existenciales (haeccidades) pronuncian diversidades de la verdad.

Pero, se insiste, ¿cómo asumir tal actitud esperando que cambie algo en el mundo?, ¿es posible 
desde los espacios de ejercicio periodístico y comunicacional adoptar posturas a partir de las cuales puedan concretarse cambios?, ¿es posible desde lugares propios de la racionalidad del mercado posicionarse disruptivamente en relación con las condiciones que impregnan cada espacio vital? Se plantea que el abordaje de una problematización en esta línea puede encontrar un buen inicio en la reflexión sobre las posibilidades de los discursos para producir realidades. Estos podrían ser asumidos, en todo caso, como construcciones emitidas desde lugares duros de organización que como misión política guardan el imperativo del disciplinamiento, la sumisión, la aceptación de subjetividades partícipes de un determinado sistema productivo.

Piénsese en las condiciones de práctica de un comunicador o periodista inserto en un medio tradicional, un periódico o un canal de televisión estructurado en una lógica gerencial afín a los cánones administrativos de la economía de mercado, que pondera la productividad y que es parte de un holding mediático que lo contiene, poseedor de otros medios o empresas que tal vez abarquen otros rubros del mercado. Siguiendo a Deleuze y Guattari, se podría asumir que la trayectoria vital y profesional de este comunicador estaría plegada por líneas duras de organización al continuar con los itinerarios trazados por las instituciones, las empresas y el estatuto del trabajo formal. Pero esas líneas pueden simultáneamente estar atravesadas por otras más flexibles, disruptivas, generadoras de quiebres en los tránsitos vitales y que representan posibles riesgos para lo molar. Pero ¿qué son estas líneas? Según los autores,

Uno ya no es más que una línea abstracta, como una flecha que atraviesa el vacío. Desterritorialización absoluta. Uno ha devenido como todo el mundo, pero a la manera en que alguien no puede devenir como todo el mundo. Uno ha pintado el mundo sobre sí mismo, y no a sí mismo sobre el mundo. No debe decirse que el genio es un hombre extraordinario, ni que todo el mundo tiene genio.
Genio es aquel que sabe hacer de todo-el-mundo un devenir (quizá Ulises, la ambición fallida de Joyce, medio lograda por Pound). Uno ha entrado en devenires-animales, devenires-moleculares, por último, devenires imperceptibles. "Estaba definitivamente del otro lado de la barricada. La horrible sensación de entusiasmo continuaba (...). Trataré de ser un animal lo más correcto posible, y si me arrojáis un hueso con bastante carne encima puede que sea incluso capaz de lameros la mano". ¿Por qué ese tono desesperado? La línea de ruptura o de verdadera fuga ¿no tendría su peligro, todavía peor que los otros? Es tiempo de morir. En cualquier caso, Fitzgerald nos propone la distinción de tres líneas que nos atraviesan, y componen "una vida" (título a lo Maupassant). Línea de corte, línea de fisura, línea de ruptura. La línea de segmentaridad dura, o de corte molar; la línea de segmentación flexible, o de fisura molecular; la línea de fuga o de ruptura, abstracta, mortal y viviente, no segmentaria. (Deleuze y Guattari, 2002, p. 204)

En el descrito comunicador, la línea dura de organización genera un impacto en su cuerpo, primer territorio sobre el que se ejerce el gobierno, en cuanto énfasis de continuidad de un estereotipo estético estimulado desde la centralidad. Probablemente no luzca muy diferente al yupi posmoderno, concretando la imagen de un cuerpo disciplinado por el mandato molar, que sin embargo no está exento de experimentar resquebrajaduras en la solidez de su semiosis.

Porque la emisión también es posible de realizarse desde lugares-otros, tal vez no oficiales, moleculares, que se atreven a configurar cuerpos cuyos devenires cuestionan la organización. Las estéticas de estos cuerpos con trayectorias alternativas a las avenidas principales y autopistas crean senderos y huellas de cabras con ropajes que les permiten transitar por los campos abiertos, inventando los pequeños caminos, pero elevando una inquisidora mirada hacia la carretera. Se trata de cuerpos indóciles que, a partir de su indisciplina, se niegan al sometimiento del mandato que 
pretende organizar, sujetar y ordenar, que resisten y crean "trazados de cartografías micropolíticas provocando otros modos de estar y hacerse en el mundo, deviene método menor de descomposición del dispositivo neoliberal" (Martínez Posada y Ochoa Ordóñez, 2017, p. 231).

La indocilidad conlleva toda una política de denuncia y visibilización del gobierno ejercido en aquellos carriles de la gran carretera, donde los cuerpos transitan en una única y preestablecida dirección, señalizada, resultante del diseño de arquitectos e ingenieros. En las quebradas de los senderos de cabra del campo comunicacional es posible hallar toda una variedad de experimentaciones que encuentran vías de existencia por fuera de los circuitos tradicionales e incluso formales, de los discursos y flujos de poder.

Se abre la reflexión acerca de las posibilidades de democratización que emergen como estímulo del acceso a las nuevas tecnologías infocomunicacionales, pues ha dejado de ser requisito el disponer de grandes infraestructuras técnicas o de vastos recursos humanos para transmitir por televisión o por radio, o para publicar un artículo. La economía y accesibilidad de los gadgets da lugar a una diversificación de medios en el escenario comunicacional que permite pensar que, si bien hay verdades que son duras, mayoritarias o hegemónicas, lejos están de ser totalitarias. Recorrer estos senderos demanda una disposición de cuerpos apostados para una disputa por la construcción de otros mundos:

Es pues la existencia-el cuerpo, una experimentación estética, ética, política, rizomática que pliega y teje el dispositivo, entonces la palabra producir se descompone y ya no significa capital, sino expresa creación de líneas de fuga, de dispositivos rizomáticos, de cuerpo sin órganos que no es, sino se hace: el Ecce Homo, la haecceidad, la subjetividad como trabajo de sí sobre sí que asume una actitud de potencia intensa de pensarse y sentirse en la soledad. Esto implica asumir una actitud esquizoanalítica que traiciona con prudencia, sobriedad y rigor para no caer en la trampa. Dicho esto, hablamos de una actitud estética de indocilidad voluntaria crítica que multiplica "no los juicios, sino los signos de existencia" (Foucault, 1999, p. 220); que hace de la propia existencia una obra de arte, tejiendo territorios múltiples, haciéndose y deshaciéndose a cada instante en una interpenetración entre el cosmos y la intimidad. (Martínez Posada y Ochoa Ordóñez, 2017, pp. 232-233)

En el campo periodístico y comunicacional, esta política puede concretizarse en los lugares, tránsitos y cuerpos que asumen con valor el pronunciamiento de ciertas verdades que no toleran que por sus arterias fluyan sin más. Porque, en definitiva, se trata de toda una actitud, una disposición espiritual que expresa las incomodidades y asume los posibles riesgos existenciales. Por actitud se hace referencia a un modo de relación con respecto a la actualidad, "una escogencia voluntaria hecha por algunos; en fin, una manera de pensar y de sentir, una manera también de actuar y de conducirse que, a la vez, marca una pertenencia y se presenta como una tarea" (Foucault, 1995b, p. 15).

¿Tal actitud justifica experimentaciones comunicacionales, estéticas y políticas esquizo con visiones de otros mundos, de otras afectividades críticas? Podría pensarse que, si los cuerpos que osan arriesgar las seguridades para emprender fugas asumen situaciones que son expresiones singulares que ya no representan cosas, sujetos o identidades, sino a esas mismas singularidades, puede estar hablándose de haeccidades:

Pero no hay que pensar que la haecceidad consiste simplemente en un decorado o en un fondo que situaría a los sujetos, ni en apéndices que fijarían al suelo las cosas y las personas. Todo el agenciamiento en su conjunto individuado resulta ser una haecceidad; se define por una longitud y una latitud, por velocidades y afectos, independientemente de las formas y de los sujetos que solo pertenecen a otro plan. El lobo, o el caballo, o el niño dejan de ser 
sujetos para devenir acontecimientos, en agenciamientos que son inseparables de una hora, de una estación, de una atmósfera, de un aire, de una vida.

La calle se compone con el caballo, de igual modo que la rata que agoniza se compone con el aire, y el animal y la luna llena se componen juntos. (Deleuze y Guattari, 2002, p. 266)

Es decir, no se trata solo del sujeto o de la cosa en términos de unidad, sino lo que expresa toda la situación en una forma accidental y con diferentes grados de intensidad, afectada y afectando a otros, lo que el cuerpo de este periodista que se aleja de las sedimentaciones duras supone como individuación, que da materialidad a manifestaciones estéticas, éticas, políticas y espirituales monstruosas como formas de resistir las capturas, de entender y de sentir la vida, trazando nuevos devenires, creando nuevos mundos desde los espacios de la comunicación.

$¿$ Es esto a lo que se refiere con esquizoperiodismo? Puede decirse que se entiende la actitud esquizo como potencia intensiva que explora vías de investigación alternativas a las tradicionales. De esta manera, el esquizofrénico no es el "enfermo que se pretende normalizar en el hospital y la familia, juntando piezas y pegándolas con medicamentos y significados, sino que es devenir minoritario del cuerpo dispuesto en un límite absoluto que disocia el Yo, la identidad, el mercado" (Martínez Posada y Ochoa Ordóñez, 2017, p. 232). Es, de esta manera, el Cuerpo sin Órganos que se encuentra al límite entre los códigos territorializantes y el socius (Deleuze y Guattari, 1985). Así, la actitud esquizo amenaza la escritura sobre la subjetividad, dando lugar al vacío, a posibles nuevos trazos.

\section{Lo parresiástico}

Michel Foucault aborda, por su parte, a estas experimentaciones en clave del virtuosismo intrínseco a toda práctica crítica al tratarse de una actitud que se arriesga a cuestionar lo establecido, lo normado y al poder mismo, para asumir la peligrosa empresa de imaginar posibilidades-otras de existencia: "Hay algo en la crítica que guarda parentesco con la virtud. En cierto modo, de lo que yo quería hablarles era, precisamente, de la actitud crítica como virtud en general" (Foucault, 1995a, p. 2).

Ahora, si bien virtuosa, asumir esta actitud crítica, la posibilidad de pronunciar otras verdades y de atentar contra el poder no es una opción gratuita, pues puede conllevar secuelas para el crítico y virtuoso emisor, es decir, para el parrhesiastés. Y eso es, verdaderamente, de lo que se tratan aqueIlos referidos ejercicios experimentales, que parecen estar dispuestos a asumir las parresiásticas consecuencias por la adopción de actitudes críticas sobre la vida, contraponiendo verdades-otras a las del capital y trabando luchas entre distintos regímenes de veracidad que luchan entre sí para expresar las condiciones que rodean a los sujetos, o más precisamente, regímenes de veridicción (Foucault, 2007, pp. 43-67).

En el campo mediático, estas luchas se evidencian en diversos lugares y espacios: los referidos $E I$ Destape, ElDiario.es, MediaPart, y La Nueva Prensa -entre muchos otros- ofrecen verdades inquisidoras de las lecturas del mundo que se ejercen desde los centros operados por el imperio. En su momento, muchos de estos medios fueron iniciados y son gestionados por profesionales de prensa que antes habían sido despedidos de las empresas periodísticas para las que prestaban servicios, en algunos casos denunciados, desprestigiados y hasta forzados al exilio, al tiempo que los nuevos medios debieron recurrir a otras formas de financiación (por ejemplo, los ingresos por suscripciones de lectores y audiencias) para subsistir al quedar excluidos de los circuitos institucionalizados por las pautas publicitarias oficiales. Es decir, estos periodistas y medios padecieron las consecuencias propias de asumir una postura de coraje al pronunciar ciertas verdades que resultaban (y lo siguen siendo) incómodas, es decir, de "decirlo todo" (Foucault, 1992, p. 98). Esto es, en términos de Foucault (2004), 
La parresía es una forma de actividad verbal en la que el hablante tiene una relación específica con la verdad a través de la franqueza, una cierta relación con su propia vida a través del peligro, un cierto tipo de relación consigo mismo o con otros a través de la crítica (autocrítica o crítica a otras personas) y una relación específica con la ley moral a través de la libertad y el deber. Más concretamente, la parresía es una actividad en la que un hablante expresa su relación personal con la verdad, y arriesga su propia vida porque reconoce el decir la verdad como un deber para ayudar o mejorar a otras personas (y también a sí mismo). En la parresía, el hablante hace uso de su libertad y escoge la franqueza en lugar de la persuasión, la verdad en lugar de la falsedad o el silencio, el riesgo de muerte en lugar de la vida y la seguridad, la crítica en lugar de la adulación y el deber moral en lugar del propio interés y apatía moral. (p. 46)

En esta línea, el parresiastés por excelencia no parece ser otro sino el mismo Sócrates, y se podría decir que, en el tiempo presente, periodistas como Roberto Navarro (El Destape), Horacio Verbitsky (El Cohete a la Luna), Ignacio Escolar (ElDiario.es) y Gonzalo Guillén (La Nueva Prensa) o también GuiIlermo Cano (El Espectador) pueden constituirse en representantes de aquellos que optan por asumir los riesgos que conlleva el pronunciamiento de la verdad con sus consecuencias éticas y políticas y, de este modo, una determinada relación con el poder. No obsta mencionar que Navarro (crítico de la administración de Mauricio Macri como presidente de Argentina) inició su emprendimiento mediático tras ser cesanteado del canal privado de televisión C5N; que Verbitsky lanzó su portal El Cohete a la Luna tras dejar de contar con espacios en Página/12 y filtrarse el audio en el que el entonces presidente Macri mencionaba los nombres de 562 personas que "si los pusiéramos en un cohete a la Luna, el país cambiaría tanto" (Cantón, 2017), listado que integraba el mismo Verbitsky (El Cohete a la Luna, 2019); que Escolar fundó ElDiario.es para disponer de un espacio en el que pudiera publicar importantes hechos de corrupción en el gobierno y la realeza españolas, así como de otros círculos de poder de toda Europa, para los que no encontraba lugar en los medios tradicionales; que en su momento Guillermo Cano pagó con su vida por desafiar el poder del narcoterrorismo en Colombia. Se tratan todos de ejemplos de comunicadores que experimentaron sus respectivas parresías, resistiendo el poder con la crítica.

$\mathrm{Al}$ abordar estos asuntos se pretende cuestionar el presente con el propósito de transformarlo, así como a los sujetos y las subjetividades en cuanto ejercicio de problematización de los modos de ser de quienes actúan en la producción, reproducción o crítica del constructo simbólico neoliberal. La crítica que se practica no es otra que la de un presente histórico, del ahora. Y, en el caso específico del trayecto investigativo de "La producción biopolítica de la subjetividad del periodista en América Latina", haciendo foco en los dispositivos de gobierno que operan sobre la subjetividad de los profesionales que asumen la tarea de desentrañar aquellos regímenes de veridicción. ¿Qué saberes se les ha propuesto?, ¿de qué dosis de poder disponen?, ¿desde qué lugares académicos, sociales y de mercado? Las facultades de periodismo entrenan a sus futuros profesionales para hacerlos capaces de esclarecer las redes no siempre evidentes que se tejen detrás de los juegos de poder, ¿qué espacios -por ejemplo, laborales- ofrece el mercado para ese ejercicio?, ¿es de interés para las esferas de poder -o para el imperio-que se cuestionen las verdades propuestas a través de sus propios dispositivos?, ¿qué riesgos conlleva la asunción de tales cuestionamientos?, ¿es posible pronunciar verdades por fuera de las esferas mayoritarias de los medios de comunicación?

\section{Conclusiones}

Así, se emprenden, más que conclusiones, algunos trazos problematizadores a modo de síntesis de lo desplegado hasta este punto. Como se planteó, la cuestión de la subjetividad del periodista 
latinoamericano, abordada en la investigación promovida en el grupo Vivencias del Doctorado en Estudios Sociales (DES) de la Universidad Distrital Francisco José de Caldas (Bogotá, Colombia), condujo al compromiso y necesidad de reflexionar sobre aquellos trayectos que desde sus mismas corporalidades acometen una crítica a la biopolítica neoliberal que en el presente se ejerce, en cuanto poder, en el campo comunicacional.

El acercamiento a estos trayectos comunicacionales críticos se propone bajo los prismas teóricos ofrecidos por Giorgio Agamben, Gilles Deleuze y Félix Guattari, y Michel Foucault, quienes desde sus específicas miradas realizan aportes a la comprensión de diversos aspectos de la biopolítica. Tal como se adelantó, por los antecedentes y rastros dejados por estos pensadores, podría asumirse que el planteamiento es de orden posestructuralista, foucaultiano, deleuziano o de alguna denominación de ese orden, aunque se prefiere indicar que se trata de una mirada crítica acerca de los procesos de producción de subjetividades. A este respecto, si bien se ofrecieron someras aproximaciones a otros aportes sobre estas preocupaciones (como los provenientes desde los Estudios Culturales y la Antropología Cultural), las inquietudes que se plasman están en relación con la propuesta inicial que Foucault hace de la biopolítica, luego continuadas por los trabajos de Deleuze y Guattari, y Agamben; también son cercanas las contribuciones de Michael Hartd y Toni Negri, Roberto Esposito, y otros.

Por otra parte, también insistiendo en lo planteado en párrafos precedentes, es preciso mencionar que muchas de estas experimentaciones críticas recurren a las bondades de las nuevas tecnologías infocomunicacionales, en cuanto a su versatilidad y accesibilidad. En este sentido, se repara en iniciativas experimentales que ni siquiera cuentan con una plataforma de emisión propia, como un portal web o una señal de televisión o radio, sino que hacen uso exclusivo e intensivo de las posibilidades que abren las redes sociales en términos de gratuidad ${ }^{1}$. Aquí, el riesgo se presenta en clave de los posibles límites en el ejercicio periodístico profesional ya que, al ser de empleo libre para cualquier usuario que disponga de un computador conectado a internet, queda abierta la puerta a un tratamiento no profesional de los asuntos que componen la agenda. Así, la desventaja en términos de infraestructuras técnicas, económicas y de recursos humanos con respecto a los grandes medios, es compensada por las experimentaciones mediáticas críticas por el ofrecimiento de miradas distintas a las mayoritarias que no obstan de ser acompañadas por un ejercicio riguroso, por ejemplo, en el tratamiento de las fuentes.

Agamben asume a estos trayectos críticos en términos de la irreverencia que implica una profanación a la propuesta simbólica neoliberal, un verdadero sacrilegio a la religión del capital, que consagra ciertos lugares de emisión en virtud de su razón política final. Para ello, lo que estas experimentaciones toman como objeto de juego es el lenguaje, que es arrebatado del manejo de las corporaciones mediáticas para ser sacralizado en una dimensión mundana y terrenal.

Sin embargo, el autor establece una distinción entre lo que puede erigirse como una profanación y aquello que se limita a una secularización política del objeto de juego. Para alcanzar el rango profanatorio es preciso preguntarse si los mencionados ensayos comunicacionales representan una amenaza a la vitalidad neoliberal. Propone la reflexión acerca de verdades que, si bien pronunciadas, no logran alterar tal orden: "Es preciso distinguir, en este sentido, entre secularización y profanación. La secularización es una forma de remoción que deja intactas las fuerzas, limitándose a desplazarlas de un lugar a otro" (Agamben, 2005, p. 102).

Pero, además, surge la necesidad de reflexionar acerca de si tales ejercicios experimentales no solo procuran visibilizar los discursos dentro de un

1 Véase aquí, por caso, el trabajo que Catamarca al Palo exhibe en sus perfiles https://www.instagram.com/catamarcaalpalo/ y https://www.facebook. $\mathrm{com} /$ catamarcaalpalo, sin disponer de una plataforma propia. 
determinado bios. Así, lo que está en controversia es la integridad de la vida misma en sus formas más elementales, es decir, con el zoe, y la situación que en el presente atraviesa la humanidad en relación con la pandemia por coronavirus lo expone, al evidenciar tensiones por la supervivencia no solo de la vida humana, sino también por el trato con la naturaleza y con el planeta, por la existencia misma.

Por su parte, en Mil mesetas. Capitalismo y esquizofrenia (2002), Gilles Deleuze y Félix Guattari apuestan a ver ciertas prácticas esquizo que dan lugar a experimentaciones estéticas y que, a su vez, suponen ciertos posicionamientos éticos, políticos y espirituales que implican toda una crítica a la captura del capital. Son estas prácticas las que se ponen en relación y que invitan a advertir que también se dan en el campo de la comunicación y del periodismo.

Pero más, también emerge el planteamiento de reparar en los medios de comunicación, en cuanto máquinas deseantes, como dispositivos de agenciamiento que contribuyen a alimentar el deseo en términos que van más allá de lo individual, es decir, en conexión con lo social. Estos medios pueden ser vehículos de tránsito a través de distintas líneas: de segmentariedad dura desde los medios mayoritarios y tradicionales, flexibles moleculares (por ejemplo, con los trayectos comunicacionales experimentales), y de fuga con trayectos que van más allá de los márgenes y límites demarcados por la territorialidad mediática tradicional, que ejerzan resistencias y se dirijan hacia nuevas formas de expresión y creación política.

En virtud de las líneas y trayectorias que se lleguen a trazar, estos medios pueden movilizar distintas manifestaciones de ejercicio de la micro- $y$ de la macropolítica. O, si se disparan hacia trayectorias que escapen al alcance de las concertaciones mayoritarias o flexibles, es decir, cuyas experiencias fuguen hacia devenires-otros por fuera de las esferas del Estado y de la gran política, pueden constituirse en verdaderas máquinas de guerra capaces de combatir las determinaciones de lo duro y lo molar: "la línea de fuga, cada vez que es trazada por una máquina de guerra, se convierte en línea de abolición, de destrucción de las demás y de sí misma" (Deleuze y Parnet, 1980, p. 161).

No obstante, asumir estos posicionamientos críticos no es gratuito, plantea Foucault, y desafía a pensar acerca de los riesgos que acarrea el virtuosismo del decirlo todo, es decir, a la parresía que conlleva una relación con la verdad.

Este término se refiere a la vez, a mi juicio, a la cualidad moral (la actitud, el ethos) y al procedimiento técnico indispensable para transmitir el discurso verdadero a aquel que tiene necesidad de él para constituirse en soberano de sí mismo, en sujeto de verdad respecto a sí mismo. (Foucault, 1992, p. 98)

De esta manera, el acceso a la verdad representa toda una posibilidad de erigirse en soberano de sí mismo, es decir, de un actuar sobre los márgenes de libertad de los que se dispone. Por todo esto, pensar en los trayectos comunicacionales críticos en estos términos no representa sino una invitación a la problematización y reflexión sobre el presente, a abrir intersticios con posibilidades críticas que impliquen aperturas a la construcción de mundos-otros, alternativos a los propuestos por la agenda mediática del capital y de la condición biopolítica neoliberal.

\section{Reconocimientos}

Este artículo es una instancia de avance parcial de las reflexiones enmarcadas en el proyecto de investigación titulado "La producción biopolítica de la subjetividad del periodista en América Latina (2005-2022)" que se desarrolla en el grupo de investigación Vivencias, del Doctorado en Estudios Sociales (DES) de la Universidad Distrital Francisco José de Caldas (Bogotá, Colombia). A su vez, el autor/investigador es beneficiario de la Beca Colombia de Reciprocidad para Ciudadanos Extranjeros -Cohorte 2018-, del Instituto Colombiano de Crédito Educativo y Estudios Técnicos en el Exterior (Icetex). 


\section{Referencias bibliográficas}

Agamben, G. (1998). Homo Sacer. El poder soberano y la nuda vida I. Trad. Antonio Gimeno Cuspinera. Pre-Textos.

Agamben, G. (2005). Profanaciones. Trad. Flavia Costa y Edgardo Casrro. Adriana Hidalgo Editora.

Aquino Moreschi, A. (2013). La subjetividad a debate. Sociológica, 28(80), 259-278. http://www.scielo. org. mx/pdf/soc/v28n80/v28n80a9.pdf

Batanelo García, L. (2015). Ontología crítica del presente a partir de los enunciados de calidad de la educación superior [Tesis doctoral]. Universidad del Tolima.

Cantón, M. (4 de octubre de 2017). La lista de "los 562" hombres a que apunta Macri [En línea]. Clarín.com. https://www.clarin.com/politica/lista-562-hombres-apunta-macri_0_ByHj9Cf3Z.html

Deleuze, G. (1994). ¿Quién viene después del sujeto? Zona Erógena, 18. Recuperado de https://www.afoiceeomartelo.com.br/posfsa/Autores/Deleuze, \%20 gilles/Deleuze,\%20Gilles\%20-\%20Que\%20viene\%20despues\%20del\%20sujeto.pdf

Deleuze, G. y Guattari, F. (1985). El anti-Edipo. Capitalismo y esquizofrenia. Paidós.

Deleuze, G. y Guattari, F. (2002). Mil mesetas. Capitalismo y esquizofrenia. Pre-Textos.

Deleuze, G. y Parnet, C. (1980). Diálogos. Pre-Textos.

ElCohetealaLuna.com (7 de julio de 2019). Hola, querida luna. https://www.elcohetealaluna.com/ bienvenidxs-al-cohete/

Foucault. M. (1992). Hermenéutica del sujeto. Trad. Fernando Álvarez-Uría. Ediciones de La Piqueta.

Foucault, M., (1995a). Crítica y Aufklärung [“Qu'est-ce que la Critique?"]. Trad. J. Dávila Rojas. $\Delta \alpha i \mu \omega v$. Revista de Filosofía-ULA, 8. http://www.saber.ula. ve/bitstream/handle/123456789/15896/davila-critica-aufklarung.pdf?sequence $=1$

Foucault, M., (1995b). ¿Qué es la Ilustración? Revista Colombiana de Psicología, (4), 12-19. https://revistas.unal.edu.co/index.php/psicologia/ article/view/15891

Foucault, M. (2004). Discurso y verdad en la antigua Grecia. Paidós Pensamiento Contemporáneo.

Foucault, M. (2007). El nacimiento de la biopolítica: curso en el Collège de France (1978-1979). Fondo de Cultura Económica.

Foucault, M., (2009). El gobierno de sí y de los otros: curso en el Collége de France 1982-1983 (1. ${ }^{a}$ ed.). Fondo de Cultura Económica.

Fourquet, F. (2007). La subjectivité mondiale. Une intuition de Félix Guattari [En línea]. Le Portique, 20. https://doi.org/10.4000/leportique.1354

Hardt, M. y Negri, A. (2000). Imperio. Harvard University Press. http://biblioteca.udgvirtual.udg.mx/jspui/ bitstream/123456789/1716/1/Imperio.pdf

Hernández, C. (2017). Capitalismo, separación y profanación. La crítica de la separación en Giorgio Agamben. HYBRIS. Revista De Filosofía, 8(1), 127-149. https://www.readcube.com/ articles/10.5281\%2Fzenodo.583603

Lazzarato, M. (2013). La fábrica del hombre endeudado. Ensayo sobre la condición neoliberal. (1. ${ }^{a}$ ed.). Amorrortu.

Martínez Posada, J. y Ochoa Ordóñez, C. (2017). Actitud esquizoanalítica. Esquizoanálisis, un método menor de descomposición del dispositivo capitalista. Tabula Rasa, (26), 221-245.

https://doi.org/10.25058/20112742.195

Newman, N., Fletcher, R., Kalogeropoulos, A. y Nielsen, R. (2019). Reuters Institute Digital News Report 2019. Reuters Institute for the Study of Journalism (RIS); University of Oxford. https://reutersinstitute.politics.ox.ac.uk/sites/default/files/2019-06/ DNR_2019_FINAL_0.pdf

Salinas Araya, A. (2014). La semántica biopolítica. Foucault y sus recepciones. (1. ${ }^{\text {a }}$ ed.). Cenaltes. https:// doi.org/10.5281/zenodo.13125

World Economic Forum (2020). Understanding value in media: Perpectives from consumers and industry. https://es.weforum.org/reports/value-in-media/

\section{(C) $(1) \Theta(9)$}

